\title{
An oral health promotion intervention in French pregnant women; highlights at risk subgroups for dental diseases
}

\author{
Mayard-Pons $\mathrm{ML}^{1 *}$, Rilliard $\mathrm{F}^{1,2}$, Musset $\mathrm{AM}^{1,3}$ and Farge $\mathrm{P}^{1,4}$ \\ ${ }^{1}$ Medical and Dental Department, CPRP- SNCF, 18 rue de Budapest, 75009 Paris, France \\ ${ }^{2}$ Hôpitaux Universitaires Pitié-Salpêtrière-Charles Foix, 75013 Paris, France \\ ${ }^{3}$ INSERM (French National Institute of Health and Medical Research)UMR 1109, INSERM / Université de Strasbourg. Hôpitaux Universitaires de Strasbourg, \\ Faculté de Chirurgie Dentaire, Department of Oral Health, 67000 Strasbourg, France \\ ${ }^{4}$ Université Lyon 1, Faculté d’Odontologie, Hospices Civils de Lyon, 69008 Lyon, France
}

\begin{abstract}
Objectives: To describe an oral health promotion intervention in a population of French pregnant women. In order to estimate oral health awareness in pregnancy.

Material and Methods: A cross-sectional study was conducted in a population of pregnant women through the health coverage insurance system for railway workers (CPRP SNCF). Medical and dental informations were analysed through a specifically designed scheme of information retrieval.

Results: Pregnant women ( $n=443$ ) exhibited a carious prevalence of 34\%, with a mean DMFT at 5.11( 95\% CI [4.68;5.54]). Gingival disease was the most prevalent dental disorder and the main dental treatment need for $54.18 \%$ women in the population; conservative treatment for carious lesions came as the second need for $32.73 \%$. A specific subgroup at a high risk for oral diseases was delineated. Ten percent of the studied population concentrate $33 \%$ of carious lesions.

Conclusions: This study identifies the need for promoting oral health awareness in French pregnant women. A high risk subgroup for oral diseases requires additional intervention and dental treatment needs for periodontal and conservative care. The single model appointment oral health intervention must be completed by increased information to all health professionals involved in pregnancy care and beforehand.
\end{abstract}

\begin{abstract}
Abbreviations
CPRP SNCF: Caisse de Prévoyance et de Retraite du Personnel de la Société Nationale des Chemins de Fer Français

\section{Introduction}

While oral health is a recognised component of overall health and well-being at all ages, it is of paramount importance at some specific times [1]. Recently, there has been an increased awareness of the role of maternal oral health and its potential impact on the future child. Pregnancy is a key moment in a life-time, when oral health is often neglected by women, particularly among women of low socioeconomic status [2].
\end{abstract}

Physiological changes and effects of oral diseases - tooth decay and periodontal diseases - are recognized as possible risk factors leading to adverse obstetrical outcomes [3]. Physiological changes in saliva following gastroesophageal reflux, multiplication of food intakes and decreased oral hygiene during pregnancy may explain increased carious lesions often observed [4,5]. Except for infectious or painful complications, decay does not in itself, demonstrate possible adverse obstetrical outcomes, but affects the quality of life of pregnant women [6]. In addition, lower oral health in mothers significantly results in high risk children for caries diseases and later poorer oral health; multiple cavities or active caries in mothers are a high predictor for early childhood caries (ECC) [7].

Periodontal diseases are a better documented risk for prematurity, pre-eclampsia and low birth weight rates $[8,9]$. However, recent metaanalyses and literature reviews suggest a multifactorial cause and have not shown any benefit of periodontal therapy during pregnancy towards the reduction of preterm birth rates [10,11]. Also, conflicting results exist regarding the causal link of periodontal disease in obstetric risk [12].

Assuming that rates of dental diseases are high during pregnancy, with significant implications for the mother and the child across the life course, the importance of health promotion during the prenatal period is endorsed by many professional associations and other related national priorities [13]. International and national guidelines include key recommendations towards increasing education and awareness, and in some instances preventive professional oral examination.

In France, since 2010, the High Authority of Health recommends prevention strategies for pregnant women and parents before birth. A systematic preventive oral hygiene examination, carried out by a dentist, is recommended as of the 4 th month.

In the follow-up of pregnancy, care-giving in France, mostly relies on the single medical appointment model in the field of specialized medicine; this includes a monthly medical appointment (with a midwife or a general practitioner or an ob-gyn). In regards to dental care, in addition to the recommended $4^{\text {th }}$ month preventive examination,

${ }^{\star}$ Correspondence to: Mayard-Pons ML, Medical Department, CPRP SNCF, 18 rue de Budapest, 75009 Paris, France, Tel.:+33 4950400 06; E-mail: marie-laurene.mayard@cprpsncf.fr

Key words: oral health, pregnant women, prevention, carious diseases, need for care

Received: May 10, 2018; Accepted: May 18, 2018; Published: May 23, 2018 
dental care is provided as needed to the mother either upon request for emergency or for routine examination.

Although most guidelines call for oral health promotion during pregnancy, few oral health promotion interventions during this critical period have been reported.

French workers in the national railways network (SNCF) benefit a corporate specific medical insurance coverage, for them and their related direct family members; they have a long tradition of health promotion intervention in various medical or dental fields [14].

In 2012 and 2013, the beneficiaries of this health insurance scheme represented respectively $0.8 \%$ and $0.77 \%$ of the total French population protected by a social security scheme.

As part of the medical-risk management, the dental service of the CPRP SNCF initiated, as of 2012, an oral prevention campaign for pregnant women. Here we report the results and analysis of the information gathered during the 2012-2013 campaigns. The aim of the study was to assess the existence of high risk individuals and to question the relevance of the single appointment model for prevention.

\section{Material and methods}

In order to benefit from a medical follow-up, pregnant mothers have to register their pregnancy. The design of the study was based on a single appointment evaluation by a dental professional to the choice of the patient following a third party paid intervention by the social security insurance system. The aim of this individualized prevention campaign was to raise oral health awareness of pregnant women by inviting them by mail to seek a free dental appointment with their treating dentist, with direct third-party payment and without out advance payment.

As of January 1st, 2012, all concerned individuals were mailed with an invitation letter for the dental appointment, a dental chart to be completed by their practitioner. The chart was mailed back to the dental department of CPRP-SNCF, by the dental practitioner, thus ensuring the third-party payment for the appointment.

During the appointment, the dentist had to complete the chart based on collected data upon clinical examination.

Statistical analysis of the data was performed by the medical and dental department of the CPRP-SNCF.

\section{Study population}

The target population comprised every pregnant woman affiliated with the CPRP SNCF scheme, who had registered their pregnancy before the fourteenth week of pregnancy, in accordance with the provisions of the French Public Health Code. The sample size of the population was 2083 women in 2012, 1747 in 2013.

\section{Data collection}

Data were collected through a specifically designed -chart created by all authors of this study. The chart contained self-reported data by the pregnant mother regarding her civil status, medical and dental personal history and dental examination data were reported by the dental practitioner in the course of the appointment.

The following items were noted:

\section{Self-reported information}

- Personal information:
- Age,

- Parity (first pregnancy or $>1$ pregnancy),

- Term for the pregnancy,

- Employment status (1-executing staff, 2- control staff, 3-managerial staff, 4-senior position)

- Medical and dental information

- Medical status during pregnancy

Fair (no medical conditions), diabetes, high blood pressure, other medical conditions .

- Smoking status:

Yes / no.

- Last dental appointment with a scaling session:

Less than a year, between 1 and 2 years, more than 2 years, date unknown.

\section{Data from upon clinical examination assessed by the dentist}

- Dental status with Decayed, Missing and Filled teeth (DMFT), dental charting to be completed.

- Gingival Condition Scale: qualitative rating 1 (good gingival condition) to 5 (poor gingival condition).

- Dental treatment needs for the following item: dental extractions, conservative dentistry and endodontics,prosthetics (all types), periodontal care with 2 distinct items: scaling session or root-scaling

\section{Data collection and analysis}

Overall data were collected and analysed by the insurance medical and dental department of the CPRP SNCF. The collection and processing of the data for this study were approved by the national French data protection authority (National Committee for Processed Data and Freedom-CNIL).

Data were transcribed anonymously, and the following indices were calculated: DMFT index, Significant Caries Index.

The SiC Index is the mean DMFT of the one third of the study group with the highest caries score [15].

Gingival conditions scales values were averaged. Mean (m) and SD (standard deviation) were calculated.

Statistical analysis of the data was performed using the Pearson Chi Square $\left(\chi^{2}\right)$ distribution comparison tests, the Kolmogorov-Smirnov normality test (KS), Student's $(\mathrm{t})$ average comparisons, analysis of Fisher variance $(\mathrm{F})$, and Pearson bi-varied correlation analysis(R) . The 95\% confidence intervals use the normal law and the binomial law for small numbers. The significance level is set at $\mathrm{p}=0.05$. Statistical analyses were performed using the PSPPIRE (c) 2007 software.

\section{Results}

The baseline characteristics of the population based on self-reported data in the questionnaires and insurance identification are shown in Table 1. In 2012 and 2013, 3830 women reported their pregnancy to the CPRP-SNCF, were eligible and offered with the prevention dental appointment.

Participation data were as follows: the overall response rate is at $15.35 \%$; 443 pregnant women (11.57\%) had a dental appointment; 145 
(3.79\%) informed CPRP SNCF that they declined the possibility which they felt unnecessary, as a result of an already existing dental follow-up. The abstention rate was at $84.65 \%$, (3 242 women).

Pregnancy information showed that most women answered during the $2^{\text {nd }}$ term of their pregnancy $(n=254,57.34 \%)$. Whereas $45.82 \%(n=$ 203) of the participants were first pregnancies, $34.76 \%$ were multiparous $(\mathrm{n}=154)$, however $19.4 \%(\mathrm{n}=86)$ of the patients did not answer the item. Their difference was not statistically significant between the ranks of the pregnancies in the population $(\mathrm{p}=0.07)$.

Regarding the age at pregnancy, the mean age of the population is at 31.16 years with a normal distribution ( $\mathrm{KS} \mathrm{Z}=1.17, \mathrm{p}=0.11$ ). First pregnancy women are on average younger at 29.54 years $(n=203$, $\mathrm{SD}=4.82$ ), whereas multiparous women have an average age at 32.97 years $(\mathrm{n}=154, \mathrm{SD}=4.19)$, this difference is statistically significant $(\mathrm{p}$ $<0.01$ ). When looking at the employment status, executing staff women are significantly younger than those belonging to other categories $(\mathrm{p}=$ $0.03)$.

Self-reported medical and smoking status of the patients is presented in Table 2. Self- reported smoking showed a high proportion of 358 women $(80.81 \%)$ were non-smoking. Smokers represented a smaller proportion of 42 subjects $(9.48 \%)$; however, a similar number of women (43 subjects, 9.71\%) did not answer this item. Medical conditions during pregnancy showed that 386 women $(87.13 \%)$ reported no medical problems in the course of their pregnancy. Medical conditions including diabetes and high blood pressure were present in $4.51 \%$ of the population (20 patients), (Table 2).

Outpatient dental appointments results are presented in Table 3 and Figure 1. The DFMT index was calculated for the whole population. The average DMFT of the population is at 5.11 (95\%CI [4.68;5.54]). The proportion of caries -free women $(\mathrm{DMFT}=0)$ is $18.06 \%(\mathrm{n}=$ 80). Caries prevalence in the study population was estimated at 34.09 $\%(\mathrm{n}=151)$ through the D component of the DFMT index with at least one untreated carious lesion. The mean DMFT is composed in decreasing order of importance by the component $\mathrm{F}(\mathrm{m}=3.94)$, then the component $\mathrm{D}(\mathrm{m}=0.77)$ and $\mathrm{M}(\mathrm{m}=0.40)$ (Table 3$)$. The differences observed between the averages of these three components are statistically significant $(\mathrm{p}<0.01)$. As expected, the average DMFT index increases significantly with age $(\mathrm{p}<0.01)$ as does the number of missing teeth overall with age $(\mathrm{R}=0.3, \mathrm{p}<0.01)$. Conversely, the analysis of variance shows no statistically significant difference between the DMFT index and the employment status, whereas the number of missing teeth that are not replaced is inversely correlated with the employment status $(\mathrm{R}=0.3, \mathrm{p}<0.01)$.

Further analysis of the carious status was carried on by calculating the Significant Caries index ( $\mathrm{SiC}$ index).The $\mathrm{SiC}$ index refers to the one-third of the population ( $\mathrm{n}=148)$ with the highest DMFT scores. Here, the average $\mathrm{SiC}$ is at 10.49 ; it is twice the average of the total population of the study (Figure 1). Women in this high-risk subgroup

Table 1. Baseline characteristics of the population

\begin{tabular}{|c|c|c|c|c|}
\hline & & Subjects (N) & $\%$ of sample & 95\% Confidence Interval \\
\hline \multirow[t]{6}{*}{ Responding rate } & & $2012-2013$ & & \\
\hline & Total pregnant women / sent forms: & 3830 & & \\
\hline & - Non responding: & 3242 & 84.65 & {$[84.09 ; 85.20]$} \\
\hline & - Responding: & 588 & 15.35 & {$[14.05 ; 16.66]$} \\
\hline & Returned information & 443 & 11.57 & {$[10.60 ; 13.07]$} \\
\hline & Declined appointment & 145 & 3.79 & {$[1.16 ; 6.42]$} \\
\hline \multirow[t]{5}{*}{$\begin{array}{c}\text { Pregnancy Term at responding } \\
\text { time }\end{array}$} & & 443 & & \\
\hline & 1st trimester & 12 & 2.71 & {$[1.41 ; 4.68]$} \\
\hline & 2nd trimester & 254 & 57.34 & {$[51.5 ; 63.16]$} \\
\hline & 3rd trimester & 104 & 23.48 & {$[14.3 ; 32.60]$} \\
\hline & Non responding & 73 & 16.48 & {$[5.59 ; 27.37]$} \\
\hline \multirow[t]{4}{*}{ Pregnancy rank } & & & Mean Age & \\
\hline & First pregnancy & 203 & $29.54^{*}$ & {$[28.88 ; 30.20]$} \\
\hline & Multiparous & 154 & $32.97 *$ & {$[32.31 ; 33.63]$} \\
\hline & Non reponding & 86 & 31.72 & {$[30.85 ; 32.59]$} \\
\hline \multirow[t]{5}{*}{ Employment status } & Executing staff & 247 & $30.43^{*}$ & {$[29.82 ; 31.04]$} \\
\hline & Control staff & 110 & $31,88^{*}$ & {$[31.10 ; 32.66]$} \\
\hline & Managerial staff & 73 & $32,26 *$ & {$[31.24 ; 33.28]$} \\
\hline & Senior position & 13 & 32,62 & {$[29.69 ; 35.55]$} \\
\hline & Total & 443 & 31,16 & {$[30.72 ; 31.60]$} \\
\hline
\end{tabular}

*statistically significant difference: $\mathrm{p}<0.01$ for pregnancy ranking and employment status

Table 2. Self-reported medical conditions and smoking status $(\mathrm{N}=443)$

\begin{tabular}{|c|c|c|c|c|}
\hline & & Subjects (N) & \% of sample & 95\% Confidence Interval \\
\hline \multirow[t]{5}{*}{ Medical conditions } & Fair medical condition & 386 & 87.13 & {$[82.41 ; 91.85]$} \\
\hline & High blood pressure & 8 & 1.81 & {$[0.78 ; 3.53]$} \\
\hline & Diabetes & 6 & 1.35 & {$[0.50 ; 2.92]$} \\
\hline & Other medical conditions & 5 & 1.13 & {$[0.37 ; 2.61]$} \\
\hline & Non responding & 37 & 8.35 & {$[5.95 ; 11.33]$} \\
\hline \multirow[t]{3}{*}{ Smoking status } & Non smoking & 358 & 80.81 & {$[75.91 ; 85.71]$} \\
\hline & Smokers & 42 & 9.48 & {$[6.92 ; 12.6]$} \\
\hline & Non responding & 43 & 9.71 & {$[7.11 ; 12.85]$} \\
\hline
\end{tabular}


Table 3. Data from clinical examination

\begin{tabular}{|c|c|c|c|c|c|c|c|}
\hline DMFT Index & & $\mathbf{N}$ & Mean & SD & Min & Max & $95 \%$ CI \\
\hline & & 443 & 5.11 & 4.57 & 0 & 20 & {$[4.68 ; 5.54]$} \\
\hline - Decayed & & 151 & $0.77^{*}$ & 1.43 & 0 & 10 & {$[0.64 ; 0.90]$} \\
\hline - Missing & & 79 & $0.40^{*}$ & 1.28 & 0 & 12 & {$[0.28 ; 0.52]$} \\
\hline - Filled & & 312 & $3.94 *$ & 4.14 & 0 & 19 & {$[3.55 ; 4.33]$} \\
\hline \multicolumn{8}{|l|}{$* \mathrm{p}<0,01$} \\
\hline \multirow[t]{7}{*}{ DFMT with age } & & $\mathbf{N}$ & Mean & SD & Min & Max & $95 \%$ CI \\
\hline & $0-19$ & 2 & 2.5 & 3.54 & 0 & 5 & {$[0.00 ; 7.41]$} \\
\hline & $20-24$ & 31 & 3.42 & 4.07 & 0 & 19 & {$[1.99 ; 4.85]$} \\
\hline & $25-29$ & 130 & 4.58 & 4.15 & 0 & 20 & {$[3.87 ; 5.29]$} \\
\hline & $30-34$ & 174 & 5.06 & 4.56 & 0 & 18 & {$[4.38 ; 5.74]$} \\
\hline & $35-39$ & 90 & 6.1 & 4.89 & 0 & 20 & {$[5.09 ; 7.11]$} \\
\hline & 40 et + & 16 & 7.94 & 5.2 & 0 & 17 & {$[5.39 ; 10.49]$} \\
\hline \multirow[t]{5}{*}{$\begin{array}{l}\text { DFMT with } \\
\text { employment status }\end{array}$} & & $\mathbf{N}$ & Mean & SD & Min & Max & $95 \%$ CI \\
\hline & Executing staff & 247 & 5.24 & 4.63 & 0 & 20 & {$[4.66 ; 5.82]$} \\
\hline & Control staff & 110 & 5.05 & 4.65 & 0 & 20 & {$[4.18 ; 5.92]$} \\
\hline & Managerial staff & 73 & 5.12 & 4.43 & 0 & 17 & {$[4.1 ; 6.14]$} \\
\hline & Senior position & 13 & 3.15 & 3.13 & 0 & 9 & {$[1.45 ; 4.85]$} \\
\hline \multirow[t]{5}{*}{$\begin{array}{l}\text { Missing teeth not } \\
\text { replaced with } \\
\text { employment status }\end{array}$} & & $\mathbf{N}$ & Mean & SD & Min & $\operatorname{Max}$ & $95 \%$ CI \\
\hline & Executing staff & 247 & 0.4 & 1.04 & 0 & 9 & {$[0.27 ; 0.53]$} \\
\hline & Control staff & 110 & 0.22 & 0.9 & 0 & 8 & {$[0.05 ; 0.39]$} \\
\hline & Managerial staff & 73 & 0.05 & 0.28 & 0 & 2 & {$[0 ; 0.11]$} \\
\hline & Senior position & 13 & 0 & 0 & 0 & 0 & {$[0]$} \\
\hline \multirow[t]{2}{*}{$\begin{array}{l}\text { Gingival condition } \\
\text { Rating scale index } \\
{[1-5]}\end{array}$} & & $\mathbf{N}$ & $\begin{array}{l}\text { Mean rating scale } \\
\text { index }\end{array}$ & SD & Min & $\operatorname{Max}$ & $95 \% \mathrm{CI}$ \\
\hline & & 402 & 1.66 & 0.98 & 1 & 5 & {$[1.56 ; 1.76]$} \\
\hline \multirow[t]{6}{*}{$\begin{array}{l}\text { Gingival condition } \\
\text { Rating scale index } \\
\text { according to } \\
\text { previous gingival } \\
\text { care }(\mathrm{N}=\mathbf{4 0 2}) \\
\end{array}$} & & $\begin{array}{l}\text { Previous scaling } \\
\text { session }\end{array}$ & $\begin{array}{l}\text { Mean rating scale } \\
\text { index }\end{array}$ & SD & Min & $\operatorname{Max}$ & $95 \% \mathrm{CI}$ \\
\hline & $\begin{array}{c}\text { Scaling session }<1 \\
\text { year ago }\end{array}$ & 122 & $1.57^{*}$ & 0.92 & 1 & 5 & {$[1.41 ; 1.73]$} \\
\hline & $\begin{array}{c}\text { Scaling session } \\
\text { between } 1 \text { et } 2 \text { years } \\
\text { ago }\end{array}$ & 122 & $1.58 *$ & 0.91 & 1 & 5 & {$[1.42 ; 1.74]$} \\
\hline & $\begin{array}{c}\text { Scaling session }>2 \\
\text { years }\end{array}$ & 111 & $1.94^{*}$ & 1.15 & 1 & 5 & {$[1.73 ; 2.15]$} \\
\hline & $\begin{array}{c}\text { Non dated scaling } \\
\text { session }\end{array}$ & 35 & 1.4 & 0.81 & 1 & 4 & {$[1.13 ; 1.67]$} \\
\hline & Non responding & 12 & & & & & \\
\hline
\end{tabular}

$* \mathrm{p}=0,01$ between scaling sessions $<2$ years ago end scaling sessions $>2$ years ago

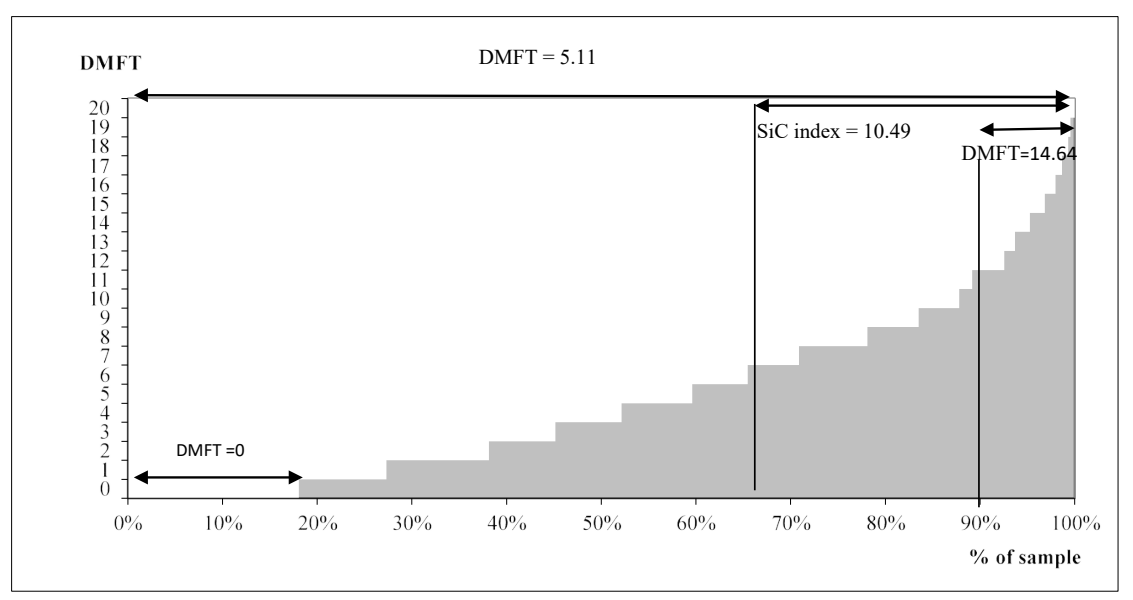

Figure 1. DMFT and Significant Caries index ( $\mathrm{SiC}$ index) 
were significantly older $(\mathrm{m}=32.12$ years, $\mathrm{SD}=4.73)$ than the other two-thirds $(\mathrm{m}=30.67$ years, $\mathrm{SD}=4.67, \mathrm{n}=295) \mathrm{p}<0.01$. There were more reported smokers in this subgroup $(\mathrm{n}=19,12.84 \%)$ than in the rest of the population $(\mathrm{n}=23,7.8 \%)$ and this difference was statistically significant $\left(\mathrm{x}^{2}(2 \mathrm{ddl})=6.9, \mathrm{p}=0.03\right)$. Hence, ten percent of all pregnant women in the study concentrate $33 \%$ of the carious problems with an average DMFT of 14.64, which is almost three times the average DMFT score (5.11) of pregnant women in the study (Figure 1).

Gingival condition was evaluated from the results of the qualitative rating scale used in this study, as noted by the dental practitioner upon the clinical examination. On a 1 to 5 scale ranging from 1 (no clinical sign of marginal inflammation), to 5 (severe gingival inflammation) the average calculated rating was at 1.66 in the study population $(n=402)$. For $55.08 \%(\mathrm{n}=244)$ the pregnant women examined, practitioners assigned a score of 1 (good) - the item was not completed in $9.26 \%$ (n $=41)$ cases.

In order to test the relative accuracy of the semi quantitative scale, we looked at the distribution according to the previous scaling sessions over 2 years. The distribution of the scale scores shows that women who had a scaling session more than 2 years ago have a significantly-higher scoring than those who had a previous session earlier than 2 years $(\mathrm{m}=$ 1.94 vs $\mathrm{m}=1.58, \mathrm{p}=0.01$ ). (Table 3 ).

Dental treatment needs were analysed from the clinical recommendations assessed by the dentist during the preventive consultation. They are presented in Table 4 . Overall 69.30\% $(n=307)$ of the population requires at least some form of dental care. The main item was scaling prophylaxis session advised for $54.18 \%(n=240)$ of the study population. Carious lesions conservative treatment came as the second most frequently needed care for almost one-third of women ( $\mathrm{n}=145$, $32.73 \%$ ). Of these, primary caries treatment care was needed in $63.45 \%$ $(\mathrm{n}=92)$ of them, $22.07 \%(\mathrm{n}=32)$ of the lesions were secondary caries and $14.5 \%(n=21)$ of women in the population requested treatment for both primary and secondary caries. Prosthetic dentistry was advised for $16.25 \%$ of women, mostly (94.5\%) for fixed single crown. The needs for endodontic or surgical procedures (involving tooth extractions) were noted sporadically, in than $5 \%$ of the study population.

\section{Discussion}

This study reports the results of an oral health promotion intervention in a population of French pregnant women. While direct data on the study population are reported, the design of the health intervention gives some informations in regard to oral health literacy among the patients and care givers.

The oral health campaign was designed and based on the singleappointment model with a dental professional based on a voluntary response to a personalized reminder letter. The answer rate was at $15.35 \%$ reflecting the self-reported compliance of the population. This demonstrates the low knowledge of the importance of oral health during the pregnancy, both to the mothers and the health professional

Table 4. Dental treatment needs $(\mathrm{N}=443)$.

\begin{tabular}{|l|l|l|l|}
\hline \multicolumn{1}{|l|}{} & N & \% of sample & 95\% CI \\
\hline Dental treatment needs overall & 307 & 69.30 & {$[64.14 ; 74.46]$} \\
\hline Scaling prophylaxis session & 240 & 54.18 & {$[47.88 ; 60.48]$} \\
\hline Conservative dentistry overall & 145 & 32.73 & {$[25.09 ; 40.37]$} \\
\hline primary caries only & 92 & 63.45 & {$[53.61 ; 73.29]$} \\
\hline secondary caries only & 32 & 22.07 & {$[7.70 ; 36.44]$} \\
\hline Primary and secondary caries & 21 & 14.48 & {$[0 ; 29.53]$} \\
\hline
\end{tabular}

involved in pregnancy care in France.

Response rates to promotion interventions, with similar designs, are usually low; for other medical conditions, such as diabetes or obesity responses rates were reported around 40\% [16,17]. A single solicitation by postal mail was used in this study and it is likely that multiple solicitations by internet or direct phone contact may have enhanced the response rate.

While integration of oral health promotion in general care has been highly recommended by the World Health Organization, physicians' knowledge of and adherence to improving oral health remains low [18-20].

In the study population, most of the women responding to the dental appointment were in the second term of the pregnancy, in accordance with the recommendation of the French High Authority for Health (HAS), which advises a dental visit during the second semester. Despite European guidelines, no specific professional guidelines exist through other professional organisations in France, thus reflecting the low perception of screening and early dental care in pregnancy. Owing to the design of the study, it can be assumed that the responding participants perceived a need for dental follow-up. Thus, this study identified a subset of patients with a higher awareness for health promotion interventions.

The sample characteristics of the study population compared to previously reported studies in the French population in regard to age [21], employment status [21] and medical overall conditions [22]. Caries prevalence is similar on the lower side, to previously describe international studies $[23,24,25]$. In addition, the importance of medico-economic organisation of dental care accounts for the result of oral health intervention [26]. Here, the benefits of widespread social protection, the stability for employment at the railway corporation (CPRP SNCF) likely account for the low caries incidence in the overall study population.

Among the participants, $69.3 \%$ of the women were in need for dental care. Gingival conditions (54.2\%) were the most needed care; caries treatment was diagnosed in $32.8 \%$ of the patients. Moreover, the data identified a subset of pregnant women in the population that concentrate $33 \%$ of oral diseases and treatment needs. This subset of high risk patients for oral diseases was older women, primiparous, more likely with an executing staff employment status and smoking patients. Gingival condition accounts for most of the dental treatment needs in pregnant women; while this has been widely recognized in previous literature $[27,9,10]$, the effect of periodontal treatment on a decreased obstetrical risk, is more controversial $[28,29]$. However, the study identifies strong inequalities in oral health since $1 / 10$ of the study population concentrates $1 / 3$ of caries lesions. Since the mother's oral health is a key factor for the oral health of the child [30], these women likely combine several risk factors in pregnancy and the single appointment intervention model proved adequate here in providing information and care. These patients would likely benefit from specifically-designed programs towards increasing their oral health literacy [31]. Caries risk assessment models have been recently reviewed and no specific multivariate model could be identified for any specific population such as pregnant women; baseline caries prevalence was the most accurate single predictor in all age groups [32].

In order to initiate significant behavioral changes in oral health behaviour, outcome of promotion interventions should be appreciated. Lack of understanding of the relationship between oral health and pregnancy by health professional, noted in several studies $[33,34]$ could 
be overcome by emphasizing multidisciplinary guidelines for nondental and dental professional involved in managed care pregnancy surveillance [35]. Here, the evaluation of the dental status and treatment need was adequately retrieved through the practising dentist of the patient, though it has been reported that dentists express discomfort with treatment modalities during pregnancy [13]. Further evaluation might indicate whether a single-appointment intervention can yield to effective treatment in high risk populations, thus translating knowledge into prevention and care.

\section{Disclosure statement}

The authors report no conflicts of interest.

\section{References}

1. Nicolau B, Thomson WM, Steele JG, Allison PJ (2007) Life course epidemiology: concepts and theoretical models and its relevance to chronic oral conditions. CommunityDent Oral Epidemiol 35:241-249. [Crossref]

2. Vergnes JN, Pastor-Harper D, Constantin S, Bedos C, Kaminski M, et al. (2013) Perceived oral health and the use of dental services during pregnancy:the MaterniDent study. Sante Publique. 25:281-292. [Crossref]

3. Vergnes JN, Kaminski M, Lelong N, Musset AM, Sixou M, et al. (2011) Maternal dental caries and pre-term birth: results from the EPIPAP study. Acta Odontol Scand. $69: 248-256$. [Crossref]

4. Laine MA (2002) Effect of pregnancy on periodontal and dental health. Acta Odontol Scand. 60:257-264.

5. Silk H, Douglass AB, Douglass JM, Silk L (2008) Oral health during pregnancy. $A m$ Fam Physician. 77: 1139-1144.

6. Lu HX, Xu W, Wong MC, Wei TY, Feng XP (2015) Impact of periodontal conditions on the quality of life of pregnant women: a cross-sectional study. Health Qual Life Outcomes 13: 67. [Crossref]

7. Ramos-Gomez FJ, Crystal YO, Wai M, Crall JJ, Featherstone JDB (2010) Pediatric dental care: prevention and management protocols based on caries risk assessment. $J$ Calif Dent Assoc. 38: 746-761. [Crossref]

8. Nabet C, Lelong N, Colombier ML, Sixou M, Musset AM, et al. (2010) Maternal periodontitis and the causes of preterm birth the case-control Epipap study. $J$ Clin Periodontol. 37: 37-45. [Crossref]

9. Boggess KA, Berggren EK, Koskenoja V, Urlaub D, Lorenz C (2013) Severe preeclampsia and maternal self-report of oral health, hygiene, and dental care. J.Periodontol 84: 143-151. [Crossref]

10. Vanterpool SF, Tomsin K, Reyes L, Zimmermann LJ, Kramer BW, et al. (2016) Risk of adverse pregnancy outcomes in women with periodontal disease and the effectiveness of interventions in decreasing this risk: protocol for systematic overview of systematic reviews. Syst Rev. 5:16. [Crossref]

11. Xiong X, Buekens P, Goldenberg RI, Offenbacher S, Qian X (2011) Optimal timing of periodontal disease treatment for prevention of adverse pregnancy outcomes: before or during pregnancy? Am J Obstet Gynecol. 205:111,e1-6

12. Schwendicke F, Karimbux N, Allareddy V, Gluud C (2015): Periodontal Treatment for Preventing Adverse Pregnancy Outcomes: A Meta- and Trial Sequential Analysis. PLoS ONE 10: e0129060. [Crossref]

13. Vamos CA, Thompson EL, Avendano M, Daley EM, Quinonez RB, et al. (2015) Oral health promotion interventions during pregnancy: a systematic review. Community Dent Oral Epidemiol 43: 385-39. [Crossref]

14. Mayard-Pons ML, Rilliard F, Libersa JC, Musset AM, Farge P (2015) Database analysis of a French type 2 diabetic population shows a specific age pattern of tooth extractions and correlates health care utilization. J Diabetes Complications. 29: 993-997 [Crossref]

15. Campus G, Solinas G, Maida C, Castiglia P. The 'Significant Caries Index' (SiC): a critical approach. Oral Health Prev Dent. 2003;1(3):171-8

16. Ko JY, Dietz PM, Conrey EJ, Rodgers L, Shellhaas C, Farr SL, Robbins CL.Gestational diabetes mellitus and postpartum care practices of nurse-midwives. J Midwifery Womens Health. 2013 Jan-Feb;58(1):33-40.

17. Skip Rizzo A, Lange B, Suma EA, Bolas M (2011) Virtual reality and interactive digital game technology: new tools to address obesity and diabetes. J Diabetes Sci Technol. 5:256-264. [Crossref]
18. Rabiei S, Mohebbi SZ, Patja K, Virtanen JI (2012) Physicians' knowledge of and adherence to improving oral health. BMC Public Health 12: 855. [Crossref]

19. George A, Dahlen HG, Reath J, Ajwani S, Bhole S, et al. (2016) What do antenatal care providers understand and do about oral health care during pregnancy: a cross-sectional survey in New South Wales,Australia. BMC Pregnancy Childbirth. 16: 382. [Crossref]

20. Golkari A, Khosropanah H, Saadati F (2013) Evaluation of knowledge and practice behaviours of a group of Iranian obstetricians, general practitioners, and midwives, regarding periodontal disease and its effect on the pregnancy outcome. J Public Health Res. 2: 15 .

21. http://www.insee.fr

22. http://www.ameli.fr:Effectifs et pourcentage de personnes prises en charge pour différentes pathologies et par classe d'âge selon le sexe en 2013.

23. Radnai M, Gorzo I, Nagy E, Urban E, Eller J, Novak T, et al. (2007) The oral health status of postpartum mothers in South-East Hungary. Community Dent Health. 24: 111-116. [Crossref]

24. Mobeen N, Jehan I, Banday N, Moore J, McClure EM, et al. (2008) Periodontal disease and adverse birth outcomes: a study from Pakistan. Am J Obstet Gynecol. 198: 514 e1-8. [Crossref]

25. Delemotte M, Valcarcel J, Tramini P (2013) Oral health and precariousness in pregnant women. Odontostomatol Trop. 36:14-26. [Crossref]

26. Riggs E, Yelland J, Shankumar R, Kilpatrick N. (2016) "We are all scared for the baby": promoting access to dental services for refugee background women during pregnancy. BMC Pregnancy and Childbirth $16: 12$. [Crossref]

27. Offenbacher S, Katz V, Fertik G, Collins J, Boyd D, et al. (1996) Periodonta infection as a possible risk factor for preterm low birth weight. $J$ Periodontol. 67(10 Suppl):1103-1113. [Crossref]

28. Weidlich P, Moreira CHC, Fiorini T, Musskopf ML, da Rocha JM, et al. (2013) Effect of nonsurgical periodontal therapy and strict plaque control on preterm/low birth weight: a randomized controlled clinical trial. Clin Oral Investig $17: 37-44$. [Crossref]

29. Schwendicke F, Karimbux N, Allareddy V, Gluud C (2015): Periodontal Treatment for Preventing Adverse Pregnancy Outcomes: A Meta- and Trial Sequential Analysis. PLoS ONE 10 : e0129060. [Crossref]

30. Camara S, de Lauzon-Guillain B, Heude B, Charles MA, Botton J, et al. (2015) Multidimensionality of the relationship between social status and dietary patterns in early childhood: longitudinal results from the French EDEN mother-child cohort. Int $J$ Behav Nutr Phys Act 12: 122. [Crossref]

31. Lee JY, Divaris K, Baker AD, Rozier RG, Lee SY, et al. (2011) Oral health literacy levels among a low-income WIC population. J Public Health Dent 71: 152-160. [Crossref]

32. Mejàre I, Axelsson S, Dahlén G, Espelid I, Norlund A, et al. (2014) Caries risk assessment. A systematic review. Acta Odontol Scand 72: 81-91. [Crossref]

33. Boutigny H, Moegen ML, Egea L, Badran Z, Boschin F, et al. (2015) Oral infection and Pregnancy: Knowledge of Gynecologists/Obstetricians, Midwives and Dentists. Oral Health Prev Dent. 14:41-47 [Crossref]

34. Gupta S, Jain A, Mohan S, Bhaskar N, Walia PK (2015) Comparative Evaluation of Oral Health Knowledge, Practices and Attitude of Pregnant and Non-Pregnant Women, and Their Awareness Regarding Adverse Pregnancy Outcomes. J Clin Diagn Res. 9: ZC26-ZC32. [Crossref]

35. Thoele MJ, Asche SE, Rindal DB, Fortman KK (2008) Oral health program preferences among pregnant women in a managed care organization. J Public Health Dent 68:174 177. [Crossref]

Copyright: (C2018 Mayard-Pons ML. This is an open-access article distributed under the terms of the Creative Commons Attribution License, which permits unrestricted use, distribution, and reproduction in any medium, provided the original author and source are credited. 